\title{
Physical and physiological benefits of small sided recreational handball in untrained males: relationship of body fat with aerobic capacity
}

\author{
Rakesh Tomar ${ }^{\mathrm{ABCDE}}$, John A. Allen ${ }^{\mathrm{ABCD}}$ \\ King Fahd University of Petroleum \& Minerals, Saudi Arabia
}

Authors' Contribution: A - Study design; B - Data collection; C - Statistical analysis; D - Manuscript Preparation; E - Funds Collection.

\begin{abstract}
Background Exercise and Recreation play major role in promotion of health and fitness. Recreational exercise or sports and Study Aim can be useful in physically inactive population. The aim of study was to investigate the effect of recreational handball on body fat percent, $\mathrm{VO}_{2} \max$, blood pressure and resting heart rate. Another purpose to find relationship between $\mathrm{VO}_{2}$ max and body fat percentage.

Material and Twenty-four students were randomized into intervention $(n=14)$ and control group $(n=10)$. The intervention Methods group was asked to play recreational handball for 12 weeks. Handball training was held twice a week for 30 minutes duration. The Control group performed their normal routine. Aerobic capacity measured using single-stage treadmill test. Body fat was measured with Omron Body Fat Analyzer. T-test was employed to find a significant difference in the two groups. For the relationship in aerobic capacity and body fat, Pearson Product Moment Correlation was used.

Results We found significant difference in body percent $\left(t_{22}=2.031, P=0.054\right)$. No significant difference was seen in aerobic capacity $\left(t_{22}=1.578, P=0.129\right)$, systolic blood pressure $\left(t_{22}=-1.637, P=0.116\right)$, diastolic blood pressure $\left(t_{22}=-1.562, P=0.133\right)$ and resting heart rate $\left(t_{22}=1.620, P=0.120\right)$. Significant relationship was established between body percent and aerobic capacity $(r=-5.23, n=14, p=0.055)$ in the intervention group.

Conclusions It can be concluded that recreational handball was useful in eliciting good response with respect to reduction of body fat in intervention group. However, recreation handball sessions were not effective in reducing blood pressure, resting heart and aerobic capacity among untrained males. A significant relationship was observed in $\mathrm{VO}_{2}$ max and percent body fat.

Keywords: $\quad$ small sided games, $\mathrm{VO}_{2} \max$, team sports, blood pressure, resting heat rate
\end{abstract}

\section{Introduction}

Exercise and recreation play major role in promotion of health and fitness. Recreational exercise or sports can be useful in physically inactive population. Physical inactivity as per $\mathrm{WHO}$, is a major risk factor for global mortality [1]. Low physical fitness level is result of sedentary lifestyle. Participating regularly in physical activity proved to be beneficial to individual health and supervised training interventions are an important took for preventing and treating lifestyle related diseases [2,3] There is a concern about poor adherence to prescribed exercise programmes specially in long term [4].

It has been reported that there are certain team games which can bring a sustainable training intervention that can effectively induce large range fitness and health benefits and that too in motivating environment, although not much research has been done in this area [5]. Further in Denmark and also worldwide, there is high dropout rate in response to traditional exercise regime $[4,6]$. There is a need to strategize and identify new ideas and activities which can motivate individuals to remain fit and active providing long lasting changes in their lifestyle and prolonged physiological perspectives [7].

It has been found in recent studies that recreational

o Rakesh Tomar, John A. Allen, 2021

doi:10.15561/20755279.2021.0601 handball has high aerobic and anaerobic demands and it is intermittent high-intensity exercise mode, similar to the competitive version [8]. Demands in recreational handball are similar to as described in for recreational soccer [9], which has shown that different populations have a positive impact on their health and fitness levels as a result of recreational soccer practice [10-12]. Team sports have the potential to motivate and attract varied populations and can also motivate individual for sustained participation which can bring in long term changes in lifestyles [7].

Therefore, recreational handball can be a good alternative for development of cardiovascular fitness. Since recreational handball is appealing mode of exercise with large many ex-players and fans across world [13], a greater number of studies are needed to use handball for promotion and enhancement of health and physical fitness. It appears that team games can increase wellbeing in individuals just like any other physical exercises [14], therefore, it is well expected on similar lines that recreational handball would be beneficial and would have similar effects in sedentary individuals.

Therefore, we studied the effects of small sided recreational handball on $\mathrm{VO}_{2} \max$, body fat percent, resting heart and blood pressure in untrained male. We also investigated the relationship of aerobic capacity and body fat percent. 


\section{Materials and Methods}

Participants

Participants were untrained male residing in campus of King Fahd University of Petroleum \& Minerals. Total 24 participants were selected randomly following exclusion criteria. They were fully informed about the risk and written consent was obtained. This study was approved by Research Committee of King Fahd University of Petroleum and Minerals through project IN191046, 29 March, 2020. Exclusion criteria were the following: participants involved in regular physical activities with in previous one year, who were playing regular handball; participants on medications and suffering from cardiovascular diseases or obesity.

\section{Procedure}

Project was carried out for 12 weeks. Two groups were formed to study the effects. Group one was intervention with 14 participants. Group two was control with 10 subjects. Subjects were assessed and tested at the baseline and at the end of 12 week of intervention. Participants were advised not to involve in any other physical activities during the period of 12-week intervention. Twelve weeks of supervised small sided recreational handball was given to the participants in intervention group. There was total four teams. Each team consists of 4 players instead of regular seven. All games were played on handball court measuring 40x30m. All sessions were organized during evening hours. Frequency of sessions was twice a week for 30 minutes. Participants did warm up for 10 minutes which consists of jogging and handball drills. After finishing of each session participants performed cooling down exercise for 10 minutes. All the training sessions were supervised personally by the research team. Heart rate of participants in intervention group was measured by heart rate monitors during all handball training sessions.

\section{Measurements and Testing Protocols}

Age, weight, height, percent body fat was recorded at the baseline. Body fat percentage was measured using Omron body sensor. Hear rate for participants in handball training was measured by Polar FT7 Heart Rate Monitor. Blood pressure and resting heart rate was checked and recorded after resting in supine position for at least 20 minutes using Omron Blood-Pressure Monitor. $\mathrm{VO}_{2} \max$ was tested prior to exercise training programme by single stage treadmill walking test. It is test for submaximal aerobic fitness which estimates $\mathrm{VO}_{2}$ max. It was suitable for people with less risk, who were healthy, non-athletic adults with age range from 20-59 [15].

\section{Statistical Analysis}

Collected data were presented as means and standard deviation. Data were assessed for normality by Shapiro Wilks test. Baseline measurements were checked for any group differences before intervention using $\mathrm{T}$ Test. Between groups differences in delta values (post minus pre-values) were tested by Independent T Test. P-value for significance was set at 0.05 . SPSS for Windows, version 26.0, was used for statistical analysis.

\section{Results}

Participant's mean age was $19.78 \pm 1.05$ years and $19.60 \pm 0.96$ years in intervention and control groups $(P$ $=0.664)$ respectively. No adverse complications were reported. There were no significant differences at baseline between two study groups (table 1).

\section{Handball Sessions}

From initial enrolment of 26 participants, two participants withdrew from the intervention (small side handball) during the study period. Two participants in control group did not appeared for post intervention measurements. All participants were able to play vigorous game of small sided handball (Mean Average heart rate $168.32 \pm 8.60$ beats/ minute) for 30 minutes duration (Mean duration of play $28.09 \pm 2.63$ minutes). Mean Attendance in the intervention group during study period was $94.64 \%$ which shows the enthusiasm and interest of participants in recreational handball (Table 2).

Body Fat Percent and Aerobic Capacity

Analysis of data revealed improvement in body fat percent. $\mathrm{T}$ Test found significant difference in body fat percent $\left(\mathrm{t}_{22}=2.031, \mathrm{P}=0.054\right)$, with mean body fat percent was $16.74 \pm 5.29$ and $14.35 \pm 4.14$ in IG and CG respectively. We did not observe any significant improvement in $\mathrm{VO}_{2}$ max after 12 weeks of intervention between two groups $\left(\mathrm{t}_{22}=1.578, \mathrm{P}=0.129\right)$, where mean $\mathrm{VO}_{2} \max$ was $35.28 \pm 2.49$ and $36.96 \pm 3.60$ in IG and CG respectively (table 3 , Fig.1).

\section{Resting Heart Rate and Blood Pressure}

With regard to both blood pressure and resting heart rate, no significant difference was observed post

Table 1. Comparison at Baseline between Intervention and Control Group (T Test)

\begin{tabular}{llllll}
\hline Variable & \multicolumn{2}{l}{ Intervention Group $(\mathbf{n = 1 4 )}$} & \multicolumn{2}{l}{ Control Group (n=10) } & \multirow{2}{*}{ P Value } \\
\cline { 2 - 5 } & Baseline & $\mathbf{1 2}$ Week & \multicolumn{2}{l}{ Baseline } & 12 Week \\
\hline Body Fat Percent & $16.98 \pm 5.26$ & $16.74 \pm 5.29$ & $14.2 \pm 4.21$ & $14.35 \pm 4.14$ & 0.180 \\
Systolic Blood Pressure (mmhg) & $114.35 \pm 6.47$ & $114.28 \pm 7.46$ & $114 \pm 11.37$ & $110.8 \pm 9.75$ & 0.923 \\
Diastolic Blood Pressure (mmhg) & $71.92 \pm 5.90$ & $72 \pm 6.64$ & $69.1 \pm 5.74$ & $65.3 \pm 2.86$ & 0.254 \\
Resting Heart Rate (bpm) & $76.42 \pm 9.59$ & $73.78 \pm 9.39$ & $77.3 \pm 6.66$ & $78.2 \pm 6.74$ & 0.807 \\
VO2 Max & $34.53 \pm 2.49$ & $35.28 \pm 2.87$ & $36.96 \pm 3.60$ & $36.38 \pm 3.51$ & 0.64 \\
\hline
\end{tabular}

Descriptive Statistics, Data shown as Means \pm SD, *significant difference at .05 
Table 2. General Characteristics of Participants

\begin{tabular}{lll}
\hline Variable & $\begin{array}{l}\text { Intervention Group } \\
(\mathbf{n = 1 4 )}\end{array}$ & $\begin{array}{l}\text { Control Group } \\
(\mathbf{n = 1 0})\end{array}$ \\
\hline Age (years) & $19.78 \pm 1.05$ & $19.60 \pm 0.96$ \\
Height $(\mathrm{m})$ & $1.71 \pm 0.04$ & $1.73 \pm 0.03$ \\
Weight $(\mathrm{kg})$ & $70.16 \pm 12.58$ & $64.36 \pm 10.94$ \\
BMI $\left(\mathrm{kg} / \mathrm{m}^{2}\right)$ & $23.76 \pm 4.27$ & $21.43 \pm 3.28$ \\
Average Heart Rate $(\mathrm{b} / \mathrm{m})$ & $168.32 \pm 8.60$ & \\
Maximum Heart Rate $(\mathrm{b} / \mathrm{m})$ & $191.68 \pm 6.33$ & \\
Playing Time $(\mathrm{min})$ & $28.09 \pm 2.63$ & \\
Attendance $(\%)$ & 94.64 & \\
\hline
\end{tabular}

Data shown as Means \pm SD and \%

Table 3. Comparison of Physical Parameters after 12 weeks (Difference between Post and Pre-Scores, Independent T Test)

\begin{tabular}{llll}
\hline Variable & $\begin{array}{l}\text { Intervention Group } \\
(\mathbf{n}=\mathbf{1 4})\end{array}$ & $\begin{array}{l}\text { Control Group } \\
(\mathbf{n}=\mathbf{1 0})\end{array}$ & P Value \\
\hline Body Fat Percent & $0.24 \pm 0.46$ & $-0.15 \pm 0.47$ & $0.054^{*}$ \\
Systolic Blood Pressure (mmhg) & $0.07 \pm 4.58$ & $3.2 \pm 4.66$ & 0.116 \\
Diastolic Blood Pressure (mmhg) & $-0.07 \pm 6.84$ & $3.8 \pm 4.46$ & 0.133 \\
Resting Heart Rate (bpm) & $2.64 \pm 5.78$ & $-0.9 \pm 4.45$ & 0.120 \\
VO2 Max & $0.75 \pm 2$ & $-0.58 \pm 2.08$ & 0.129 \\
\hline
\end{tabular}

Data shown as Means \pm SD, *significant difference at .05

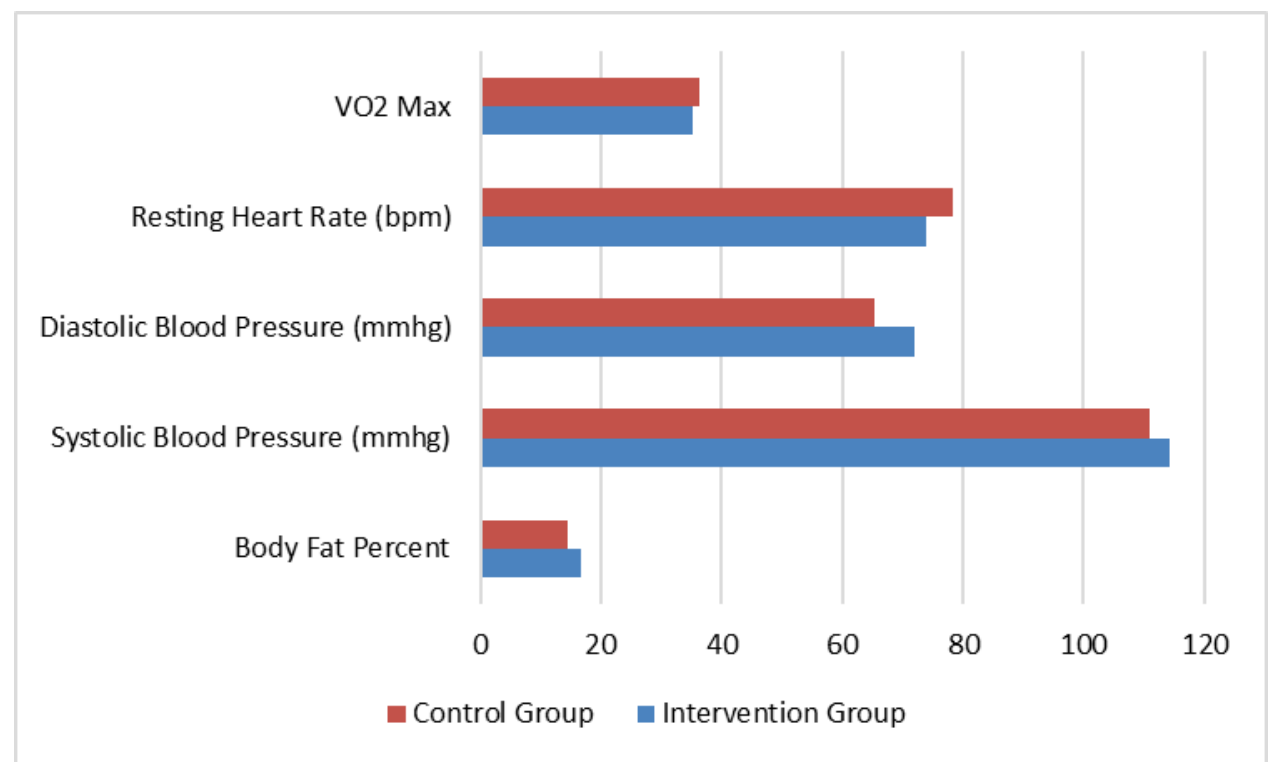

Figure 1. Mean Scores after 12 weeks of Intervention

intervention between two study groups. Systolic blood pressure did not show any significant difference $\left(\mathrm{t}_{22}=\right.$ $-1.637, \mathrm{P}=0.116)$, where systolic blood pressure post 12 week was $114.28 \pm 7.46$ and $110.8 \pm 9.75$ in IG and CG respectively. Diastolic pressure also did not show any significant improvement $\left(\mathrm{t}_{22}=-1.562, \mathrm{P}=0.133\right)$, where mean diastolic pressure post intervention was $72 \pm 6.64$ and $69.1 \pm 5.74$ in IG and CG respectively. T Test did not reveal any significant difference in resting heart rate between two groups $\left(\mathrm{t}_{22}=1.620, \mathrm{P}=0.120\right)$, where mean resting heart rate after 12 weeks was $73.78 \pm 9.39$ and $78.2 \pm 6.74$ in IG and CG respectively (table3, Fig.1).

Relationship of Aerobic Capacity with Body Fat Percent

We found significant relationship of body fat percent with aerobic capacity $(\mathrm{r}=-5.23, \mathrm{n}=14, \mathrm{p}=0.055)$ in the intervention group after 12 weeks of supervised handball programme. However, no relationship was seen between body fat and aerobic capacity $(r=-0.096, n=14, p=0.799)$ in the control group (table 4). 
Table 4. Relationship between VO2Max and Body Fat Percent

\begin{tabular}{llll}
\hline Group & VO $_{2}$ Max & Body Fat Percent & Correlation \\
\hline Intervention Group & $35.28 \pm 2.87$ & $16.74 \pm 5.29$ & $0.055^{*}$ \\
Control Group & $36.38 \pm 3.51$ & $14.35 \pm 4.14$ & 0.791 \\
\hline
\end{tabular}

Data shown as Means $\pm \mathrm{SD},{ }^{*}$ Correlation is significant at the 0.05 level (2-tailed)

\section{Discussion}

Body fat in our study reduced significantly post 12 weeks of recreational handball. Our results are similar to previous study on small sided recreational basketball [16], where body fat was reduced. Another previous study on football have shown significant reduction in body fat after 12 weeks of football intervention [17]. Our results were also supported by another study where body fat percent was significantly decreased after 3 months of half-court basketball game [18]. Small sided recreational football was effective in reducing fat percent in experimental group after 16 weeks of intervention [19]. Higher attendance percentage (94.64\%) was one of the strong aspects of this study which shows the enthusiasm among participants. This was also supported by other study which stated that students in university are more likely to appear and participate in physical activities which are social in nature and is not carried out in structured settings [20].

We have observed some improvement in aerobic capacity of intervention group. But this improvement not statistically significant. Although there were no baseline differences in two groups, but higher $\mathrm{VO}_{2} \max$ was seen among participants in the control group compare to intervention. Our intervention was also carried for only two days a week. Results of our study are contrary to previous study of similar nature done on recreational basketball, where significant difference was seen in aerobic capacity after 12 weeks of intervention [16]. Considering nature of handball game and intensity of games in present study, it was expected to see improvement in $\mathrm{VO}_{2} \max$, but our results did not fall in line with $\mathrm{VO}_{2} \max$ was significantly improved following 3 a side basketball [18]. There are number of previous studies done on small sided football that have shown improvement in aerobic fitness in untrained males [19, 21-23].

Interestingly we did not see improvement in blood pressure and resting heart rate between two study groups. Contrarily in previous study resting heart rate reduced 1015 beats per minute after 12 weeks of badminton sessions [24]. Our results were not in line with other studies where resting heart rate was reduced after 3 months of small sided basketball [18], lower resting heart rate reported after 16 weeks of recreational football [19]. Blood pressure also failed to show any significant improvement in present study. Our results were supported by previous study where blood pressure did not show any significant after small sided basketball [18], no change observed in blood pressure after 12 weeks of small sided basketball training [16]. On contrary both systolic and diastolic blood pressure was significantly reduced in previous study on recreational football [19].

We have observed high intensity throughout all handball sessions. Intensity in our study was $87.8 \%$ of HRmax, which was very similar to previous study [16] on small sided basketball ( $88 \%$ of HRmax), small sided football [19] with $86.8 \%$ of HRmax. There were other studies also that examined intensities in sports among healthy adults with an average heart rate of $82 \% \pm 2$ of HRmax [22], 89\% \pm 2 of HRmax [25], $83 \%$ of HRmax [21] and $82 \% \pm 2$ HRmax [23].

The intervention group in our study have shown a significant relationship in $\mathrm{VO}_{2} \max$ and body fat. This relationship was negative, means with increase in $\mathrm{VO}_{2}$ max there was a decrease in body fat percent. Our results were supported by pervious study [26] where negative relationship was seen between $\mathrm{VO} 2 \mathrm{max}$ and body fat percent. Few more studies observed negative relationship between body mass and $\mathrm{VO}_{2}$ max per unit of body mass 27,28$]$.

\section{Conclusions}

Small sided recreational handball games were useful in eliciting good response with respect to reduction of body fat in intervention group. Body fat was reduced significant after 12 weeks of intervention. On the other hand, recreation handball sessions were not effective in reducing blood pressure, resting heart and aerobic capacity among untrained males. However, a significant relationship was observed in $\mathrm{VO}_{2}$ max and percent body fat.

\section{Funding}

This project was funded by Deanship of Scientific Research at King Fahd University of Petroleum \& Minerals (KFUPM) under Research Grant SB191046.

\section{Acknowledgment}

"The author(s) would like to acknowledge the support provided by the Deanship of Scientific Research (DSR) at King Fahd University of Petroleum \& Minerals (KFUPM) for funding this work through project No. SB191046."

\section{Conflict of interest}

The authors report no conflict of interest. 


\section{References}

1. World Health Organization. Physical activity. [Internet]. 2016 [updated $2021 \mathrm{Feb} 10$; cited 2021 Apr 10]. Available from: http://www.who.int/topics/physical_activity/en

2. Kiens B, Beyer N, Brage S, Hyldstrup L, Ottesen LS, Overgaard K, Pedersen BK, Puggaard L, Aagaard PG. Physical inactivity-consequences and correlations. Ugeskrift for laeger. 2007;169(25):2442-5.

3. Pedersen BK, Saltin B. Exercise as medicine - evidence for prescribing exercise as therapy in 26 different chronic diseases. Scand J Med Sci Sports, 2015;25:1-72. https://doi.org/10.1111/sms.12581

4. Middleton KR, Anton SD, Perri MG. Long-term adherence to health behavior change. American Journal of Lifestyle Medicine, 2013;7(6):395-404. https://doi.org/10.1177/1559827613488867

5. Fløtum L av, Ottesen LS, Krustrup P, Mohr M. Evaluating a Nationwide Recreational Football Intervention: Recruitment, Attendance, Adherence, Exercise Intensity, and Health Effects. BioMed Research International, 2016;2016:1-8. https://doi.org/10.1155/2016/7231545

6. Bredahl TG. Region Syddanmark/Fyns Amt Ekstern evaluering af SDU. Odense: Denmark; 2007.

7. Hornstrup T, Wikman JM, Fristrup B, Póvoas S, Helge EW, Nielsen SH, Helge JW, Andersen JL, Nybo L, Krustrup P. Fitness and health benefits of team handball training for young untrained women - a cross-disciplinary RCT on physiological adaptations and motivational aspects. Journal of Sport and Health Science, 2018;;7(2):139-48. https://doi.org/10.1016/j.jshs.2017.09.007

8. Póvoas SCA, Castagna C, Resende C, Coelho EF, Silva P, Santos R, et al. Physical and Physiological Demands of Recreational Team Handball for Adult Untrained Men. BioMed Research International, 2017;2017:1-10. https://doi.org/10.1155/2017/6204603

9. Randers MB, Nielsen JJ, Bangsbo J, Krustrup P. Physiological responseandactivityprofileinrecreationalsmall-sidedfootball: No effect of the number of players: Organizing effective recreational football. Scand J Med Sci Sports, 2014;24:130-7. https://doi.org/10.1111/sms.12232

10.Bangsbo J, Hansen PR, Dvorak J, Krustrup P. Recreational football for disease prevention and treatment in untrained men: a narrative review examining cardiovascular health, lipid profile, body composition, muscle strength and functional capacity. Br J Sports Med, 2015;49:568-76. https://doi.org/10.1136/bjsports-2015-094781

11. Milanović Z, Pantelić S, Čović N, Sporiš G, Krustrup P. Is Recreational Soccer Effective for Improving VO2max? A Systematic Review and Meta-Analysis. Sports Med, 2015;45:1339-53. https://doi.org/10.1007/s40279-015-0361-4

12.Milanović Z, Pantelić S, Sporiš G, Mohr M, Krustrup P. Health-Related Physical Fitness in Healthy Untrained Men: Effects on VO2max, Jump Performance and Flexibility of Soccer and Moderate-Intensity Continuous Running. PLoS ONE, 2015;10:e135319. https://doi.org/10.1371/journal.pone.0135319

13.Karcher C, Buchheit M. On-Court Demands of Elite Handball, with Special Reference to Playing Positions. Sports Med, 2014;44:797-814. https://doi.org/10.1007/s40279-014-0164-z

14.OttesenL,JeppesenRS,KrustrupBR.Thedevelopmentofsocial capital through football and running: studying an intervention program for inactive women: Development of social capital in women's recreational football and running. Scandinavian Journal of Medicine \& Science in Sports, 2010;20:118-31. https://doi.org/10.1111/j.1600-0838.2010.01123.x
15.Ebbeling CB, Ward A, Puleo EM, Widrick J, Rippe JM. Development of a single-stage submaximal treadmill walking test: Medicine \& Science in Sports \& Exercise, 1991;23:966-973. https://doi.org/10.1249/00005768-199108000-00014

16. Tomar R, Antony VC. Linkage of aerobic capacity and body fat percent: Effects of recreational activity on aerobic capacity, body composition, blood pressure and resting heart rate in University students. Medical Science, 2019;23(98):557-64.

17.Randers MB, Nielsen JJ, Krustrup BR, Sundstrup E, Jakobsen $\mathrm{MD}, \mathrm{Nybo}$ L, et al. Positive performance and health effects of a football training programover 12 weeks can be maintained over a 1-year period with reduced training frequency: Long-term effects of reduced-frequency football training. Scandinavian Journal of Medicine \& Science in Sports, 2010;20:80-9. https://doi.org/10.1111/j.1600-0838.2010.01091.x

18.Randers MB, Hagman M, Brix J, Christensen JF, Pedersen MT, Nielsen JJ, et al. Effects of 3 months of full-court and halfcourt street basketball training on health profile in untrained men. Journal of Sport and Health Science, 2018;7:132-8. https://doi.org/10.1016/j.jshs.2017.09.004

19.Tomar R, Antony VC. Effect of small-sided recreational soccer on metabolic controls, lipid profile and physical characteristics in untrained males. Medical Science, 2019a ;23(100):835-42.

20.Burke SM, Carron AV, Eys MA. Physical activity context and university student's propensity to meet the guidelines. Centers for Disease Control and Prevention/American College of Sports Medicine. Med Sci Monit, 2005; 11:171-6.

21.Bangsbo J, Nielsen JJ, Mohr M, Randers MB, Krustrup $\mathrm{BR}$, Brito J, et al. Performance enhancements and muscular adaptations of a 16-week recreational football intervention for untrained women: Performance effects of women's football. Scandinavian Journal of Medicine \& Science in Sports, 2010;20:24-30. https://doi.org/10.1111/j.1600-0838.2009.01050.x

22.Krustrup P, Nielsen JJ, Krustrup BR, Christensen JF, Pedersen H, Randers MB, et al. Recreational soccer is an effective health-promoting activity for untrained men. British Journal of Sports Medicine, 2009;43:825-31. https://doi.org/10.1136/bjsm.2008.053124

23.Krustrup P, Christensen JF, Randers MB, Pedersen H, Sundstrup E, Jakobsen MD, et al. Muscle adaptations and performance enhancements of soccer training for untrained men. Eur J Appl Physiol, 2010;108:1247-58. https://doi.org/10.1007/s00421-009-1319-8

24.Patterson S, Pattison J, Legg H, Gibson A-M, Brown N. The impact of badminton on health markers in untrained females. Journal of Sports Sciences, 2017;35:1098-106. https://doi.org/10.1080/02640414.2016.1210819

25.Magal M, Smith RT, Dyer JJ,Hoffman JR. Seasonal variation in physicalperformance-relatedvariablesinmaleNCAAdivision III soccer players. J Strength Cond Res, 2009; 23:2555-9. https://doi.org/10.1519/JSC.0b013e3181b3ddbf

26.Pribis P, Burtnack CA, McKenzie SO, Thayer J. Trends in Body Fat, Body Mass Index and Physical Fitness Among Male and Female College Students. Nutrients, 2010;2:1075-85. https://doi.org/10.3390/nu2101075

27.Vanderburgh PM, Katch FI. Ratio scaling of VO2 max penalizes women with larger percent body fat, not lean body mass. Med Sci Sports Exerc. 1996; 28:1204-08. https://doi.org/10.1097/00005768-199609000-00019

28.Nevill AM, Ramsbottom R, Williams C. Scaling physiological measurements for individuals of different body size. Eur $J$ ApplPhysiol, 1992; 65:110-17. https://doi.org/10.1007/BF00705066 
Information about the authors:

Rakesh Tomar; (Corresponding Author); https://orcid.org/0000-0002-3107-0867; rtau@rediffmail.com; King Fahd University of Petroleum \& Minerals; Dhahran, Saudi Arabia.

John A. Allen; https://orcid.org/0000-0001-6137-9825; cecily@kfupm.edu.sa; King Fahd University of Petroleum \& Minerals; Dhahran, Saudi Arabia.

\section{Cite this article as:}

Tomar R, Allen JA. Physical and physiological benefits of small sided recreational handball in untrained males: relationship of body fat with aerobic capacity. Physical Education of Students, 2021;25(6):339-344.

https://doi.org/10.15561/20755279.2021.0601

This is an Open Access article distributed under the terms of the Creative Commons Attribution License, which permits unrestricted use, distribution, and reproduction in any medium, provided the original work is properly cited http://creativecommons.org/licenses/by/4.0/deed.en

Received: 15.09 .2021

Accepted: 18.10.2021; Published: 30.12.2021 